\title{
Transport pathways from the Asian monsoon anticyclone to the stratosphere
}

\author{
Hella Garny ${ }^{1}$ and William J. Randel ${ }^{2}$ \\ ${ }^{1}$ Deutsches Zentrum für Luft- und Raumfahrt, Institut für Physik der Atmosphäre, Oberpfaffenhofen, Germany \\ ${ }^{2}$ National Center for Atmospheric Research, Boulder, CO, USA \\ Correspondence to: Hella Garny (hella.garny @ dlr.de)
}

Received: 5 August 2015 - Published in Atmos. Chem. Phys. Discuss.: 25 September 2015

Revised: 2 January 2016 - Accepted: 17 February 2016 - Published: 3 March 2016

\begin{abstract}
Transport pathways of air originating in the uppertropospheric Asian monsoon anticyclone are investigated based on three-dimensional trajectories. The Asian monsoon anticyclone emerges in response to persistent deep convection over India and southeast Asia in northern summer, and this convection is associated with rapid transport from the surface to the upper troposphere and possibly into the stratosphere. Here, we investigate the fate of air that originates within the upper-tropospheric anticyclone from the outflow of deep convection, using trajectories driven by ERA-interim reanalysis data. Calculations include isentropic estimates, plus fully three-dimensional results based on kinematic and diabatic transport calculations. Isentropic calculations show that air parcels are typically confined within the anticyclone for 10-20 days and spread over the tropical belt within a month of their initialization. However, only few parcels ( $3 \%$ at $360 \mathrm{~K}, 8 \%$ at $380 \mathrm{~K}$ ) reach the extratropical stratosphere by isentropic transport. When considering vertical transport we find that $31 \%$ or $48 \%$ of the trajectories reach the stratosphere within 60 days when using vertical velocities or diabatic heating rates to calculate vertical transport, respectively. In both cases, most parcels that reach the stratosphere are transported upward within the anticyclone and enter the stratosphere in the tropics, typically 10-20 days after their initialization at $360 \mathrm{~K}$. This suggests that trace gases, including pollutants, that are transported into the stratosphere via the Asian monsoon system are in a position to enter the tropical pipe and thus be transported into the deep stratosphere. Sensitivity calculations with respect to the initial altitude of the trajectories showed that air needs to be transported to levels of $360 \mathrm{~K}$ or above by deep convection to likely ( $\geqq 50 \%$ )
\end{abstract}

reach the stratosphere through transport by the large-scale circulation.

\section{Introduction}

The atmospheric circulation associated with the Asian summer monsoon leads to efficient vertical transport from the surface to the upper troposphere. The upper-tropospheric monsoon circulation consists of a large anticyclone of a size similar to the northern stratospheric winter polar vortex. Distinct tracer anomalies in the Asian monsoon anticyclone provide a signature of strong upward transport from the surface to the upper troposphere (Randel and Park, 2006; Park et al., 2007, 2008; Baker et al., 2011). Randel et al. (2010) suggested that the Asian monsoon system provides a potentially efficient pathway to the tropical stratosphere, based on satellite observations of hydrogen cyanide (HCN). The seasonality of the Asian summer monsoon and thus of transport along this pathway likely contributes to an $\mathrm{HCN}$ maximum in the tropical lower stratosphere during Northern Hemisphere (NH) summer, which then propagates vertically with the Brewer-Dobson circulation, creating a "tape recorder"like signal (Mote et al., 1996) of HCN in the tropical stratosphere (Pumphrey et al., 2008; Park et al., 2013). A number of studies have used backward trajectories to study transport through the tropical tropopause layer from heights of convective outflow to the lower stratosphere (Wright et al., 2011; Tzella and Legras, 2011; Bergman et al., 2012). Consistent with Randel et al. (2010), they conclude that, in northern summer, the Asian monsoon anticyclone is the dominant source region of young air in the lower stratosphere. A simi- 

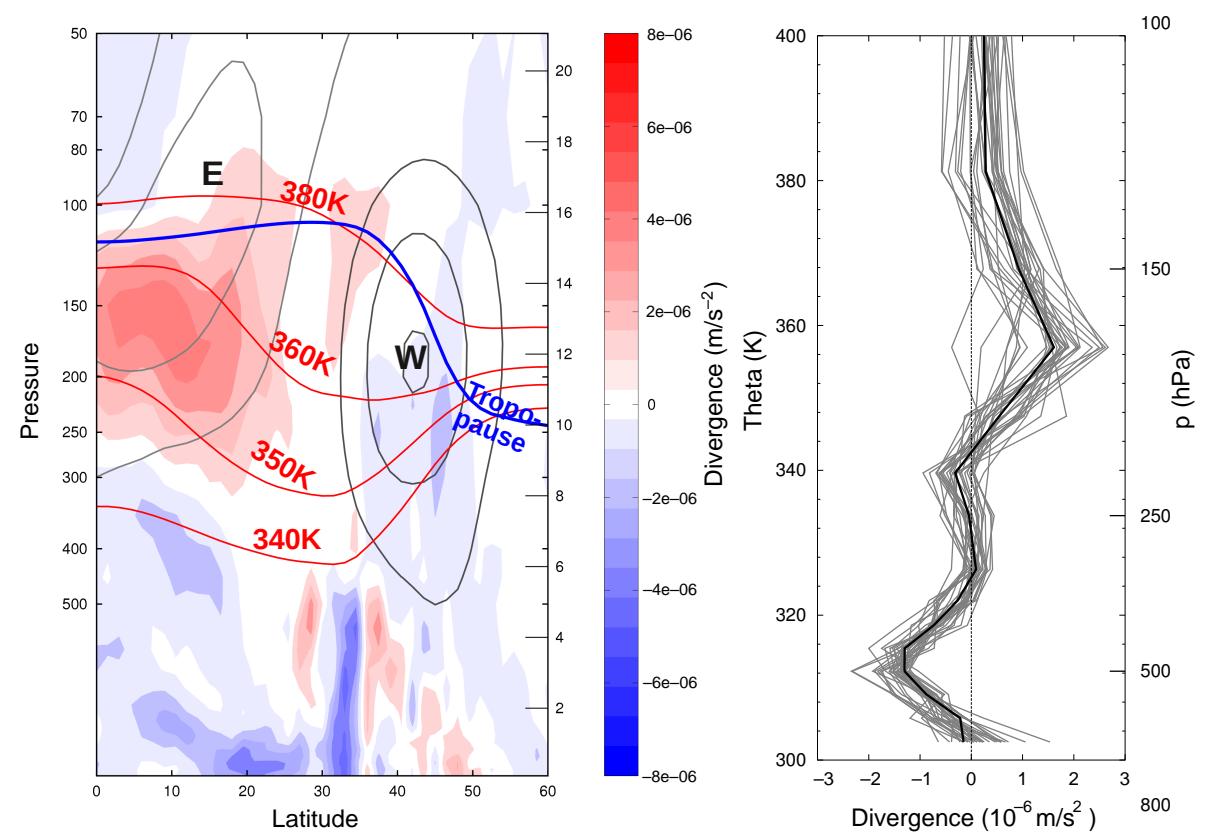

Figure 1. Left panel: mean JJA 2006 divergence over $20-120^{\circ}$ E overlaid with mean zonal winds (light gray: negative; dark gray: positive; contour interval at $10 \mathrm{~m} \mathrm{~s}^{-1}$ ). Right panel: mean profile of divergence in theta coordinates averaged over $20-120^{\circ} \mathrm{E}$ and $0-30^{\circ} \mathrm{N}$ (thick solid black line) and daily profiles (thin gray lines).

lar conclusion has recently been drawn by Orbe et al. (2015) in a systematic analysis of air mass origins in the tropical lower stratosphere.

On the other hand, the anticyclone is strongly variable in its extent, location and strength, and frequent eddy shedding indicates substantial flux out of the anticyclonic circulation (Popovic and Plumb, 2001; Garny and Randel, 2013, hereafter GR13). Dethof et al. (1999) suggested that interaction with extratropical Rossby waves could mix air from the anticyclone into the extratropics. Recently, Vogel et al. (2014) reported on a case of transport of air from the anticyclone to the northern extratropics by eddy shedding, as observed during an aircraft measurement campaign. Recent work has also highlighted that the monsoon circulation provides effective mixing between the extratropics and tropics (on the eastern and western flanks of the anticyclone), which influences the tropical seasonal cycle of ozone and other constituents (Konopka et al., 2009; Ploeger et al., 2012; Abalos et al., 2013). However, it is unclear how much air from the interior of the anticyclone, or air recently transported in deep convection, participates in this mixing to the extratropics.

The main goal of this study is to investigate the transport pathways and destinations of air originating within the upper-tropospheric Asian monsoon anticyclone. In particular, we study the efficiency, timescales and preferred pathways of transport from the anticyclone into the stratosphere. Possible pathways include quasi-horizontal mixing across the edge of the anticyclone and into the extratropical stratosphere and vertical transport into the tropical stratosphere, from where air can be transported into the deep stratosphere by the Brewer-Dobson circulation. We calculate trajectories on isentropic surfaces to study the confinement of the anticyclone and quasi-horizontal mixing and additionally investigate the full three-dimensional transport.

Previous studies have used back trajectories to evaluate the source regions of air in the tropical lower stratosphere (Wright et al., 2011; Tzella and Legras, 2011; Bergman et al., 2012) or boundary layer source regions for the uppertropospheric anticyclone (Bergman et al., 2013). In contrast, we utilize forward trajectories initialized within the uppertropospheric anticyclone. In effect, we assume that air has been transported into the upper troposphere, either by convection and/or large-scale advection, and only regard the further transport. We focus on trajectories released at the $360 \mathrm{~K}$ level, which is close to the maxima in the wind jets comprising the anticyclone and close to the level of maximum divergence in meteorological analyses (see Fig. 1). The levels of convective injection are not well known from observations: Folkins and Martin (2005) derived the heights of convective outflow in the deep tropics from observed profiles of temperature and water vapor and find strongest convective mass flux divergence around $340-365 \mathrm{~K}(10-17 \mathrm{~km})$, peaking at $347 \mathrm{~K}$. Wright et al. (2011), Tzella and Legras (2011) and Bergman et al. (2012) estimate cloud top heights from brightness temperatures (combined with precipitation in the case of Bergman et al., 2012) and infer levels of convective injection in northern summer peaking as high as 360 to $370 \mathrm{~K}$. In Sect. 5, we examine the sensitivity of our results to a broad 
range of injection heights. These calculations provide an estimate of the convective injection height necessary for air to be transported further upward and into the stratosphere.

One common problem of three-dimensional Lagrangian trajectory modeling is the uncertainty and excessive noisiness that exists in vertical motion fields. Two methods are commonly used: the kinematic approach uses vertical velocities as provided by the reanalysis products, while the diabatic approach uses diabatic heating rates as vertical velocities in a coordinate system with potential temperature as vertical coordinate. The noisy character of vertical velocities as provided by (re-)analysis data sets usually results in strong dispersion of kinematic trajectories (Ploeger et al., 2010, 2011; Schoeberl and Dessler, 2011), resulting in unrealistic transport characteristics such as excessive age of air in the stratosphere (Schoeberl and Dessler, 2011; Diallo et al., 2012). In our study, we use both kinematic and diabatic trajectory calculations to test sensitivities and estimate the uncertainties associated with the vertical velocities.

\section{Methods}

Trajectories are calculated using a simple parcel trajectory model that was implemented for the purpose of this study. The model is a standard fourth-order Runge-Kutta trajectory calculation with a time step of $0.5 \mathrm{~h}$, driven by winds and heating rates from reanalysis products. We calculate twodimensional trajectories at isentropic levels as well as full three-dimensional trajectories. The three-dimensional trajectories are calculated using both vertical velocities as given by the reanalysis fields ("kinematic" trajectories) and using heating rates as vertical velocities ("diabatic" trajectories).

The reanalysis used for both isentropic and threedimensional trajectories is the ERA-Interim data set from the European Centre for Medium-range Weather Forecasts (ECMWF) (Dee et al., 2011). We use the ERA-Interim wind fields with a horizontal resolution of $1.5^{\circ} \times 1.5^{\circ}$ latitude and longitude and 6-hourly temporal resolution. For kinematic calculations, we use data on 37 pressure levels from the surface to $1 \mathrm{hPa}$. For diabatic calculations, winds and heating rates are interpolated to 42 levels of constant potential temperature ranging from 250 to $2500 \mathrm{~K}$, with $10 \mathrm{~K}$ resolution between 250 and $450 \mathrm{~K}$. Heating rates are provided as ERAInterim forecast data, as described in detail in Ploeger et al. (2010). We follow their approach of obtaining heating rates from the 6 and $12 \mathrm{~h}$ forecasts and use total diabatic heating rates (including all-sky radiation, latent heat release and diffusive and turbulent heat transport).

Trajectory calculations focus on the Asian summer monsoon season (June-August) for the year 2006. While using only 1 year for the analysis might limit the conclusions of our study, it was found in GR13 that 2006 is no outlier in terms of strength and variability of the monsoon anticyclone (see their Fig. 5). Furthermore, no major El Niño or La Niña event that might influence the anticyclone system occurred around this year. Therefore, we expect similar results for other years without unusual conditions.

The vertical distribution of deep convective outflow in the Asian monsoon region is not well known. While convective up- and downdrafts are not resolved in the wind field, their mean effect is reflected in the large-scale winds: the anticyclone region is characterized by mean upward transport that maximizes around $330-340 \mathrm{~K}$ (or 500 to $300 \mathrm{hPa}$ ). Consequently, mean divergence is found above this region, representing mean convective outflow (note, however, that the detailed vertical profile of divergence is likely to be strongly influenced by the convective parametrization used in the reanalysis forecast model). Figure 1 (left panel) shows the structure of seasonal mean divergence in the monsoon region (together with zonal winds and isentropes), and Fig. 1 (right panel) shows daily variations of divergence throughout summer 2006. GR13 showed that potential vorticity (PV) tendencies in the monsoon region are closely linked to the analyzed divergence fields, and it is reasonable to assume that the outflow of constituents is likewise tied to mass divergence in the upper troposphere. In Fig. 1, maximum divergence occurs over $0-25^{\circ} \mathrm{N}$ for altitudes $11-15 \mathrm{~km}$, centered on isentropes $350-360 \mathrm{~K}$ (but extending over a somewhat deeper layer $345-380 \mathrm{~K})$. This behavior is consistent with estimates of injection heights inferred from cloud statistics in Wright et al. (2011), Tzella and Legras (2011) and Bergman et al. (2012). Based on this structure, we focus on studying isentropic transport at the 360 and $380 \mathrm{~K}$ levels and a vertical distribution of outflows over 340-380 K.

Isentropic trajectories are initialized every day between 1 June and 31 August of the year 2006 within the center of the anticyclone at 360 and at $380 \mathrm{~K}$. Following GR13, the center of the anticyclone is defined as the grid points between $15-45^{\circ} \mathrm{N}$ and $45-120^{\circ} \mathrm{E}$ where the $\mathrm{PV}$ is less or equal to $0.3 \mathrm{PVU}$ at the $360 \mathrm{~K}$ level and less or equal to $3 \mathrm{PVU}$ at the $380 \mathrm{~K}$ level. This procedure results in about 1000 to 2000 trajectories initialized each day at both levels, depending on the amount of low PV on each day. Trajectories are run forward for 30 days.

Three-dimensional trajectories are initialized at the $360 \mathrm{~K}$ level within the anticyclone in regions of low PV as for the isentropic calculations. Trajectories are initialized each day between 1 June and 31 August and are run forward 60 days. In Sect. 5, calculations are repeated with initial locations of trajectories within regions of most intense deep convection. In this case we use outgoing longwave radiation (OLR) as a proxy for deep convection, based on the daily gridded OLR data set from the National Oceanic and Atmospheric Administration-Cooperative Institute for Research in Environmental Sciences (NOAA-CIRES) (Liebmann and Smith, 1996; at http://www.esrl.noaa.gov/psd/data/). Trajectories are initialized in regions of low OLR (OLR less or equal $160 \mathrm{Wm}^{-2}$ ) within $0-110^{\circ} \mathrm{E}$ and $0-45^{\circ} \mathrm{N}$ at different potential temperature levels between 340 to $380 \mathrm{~K}$. 

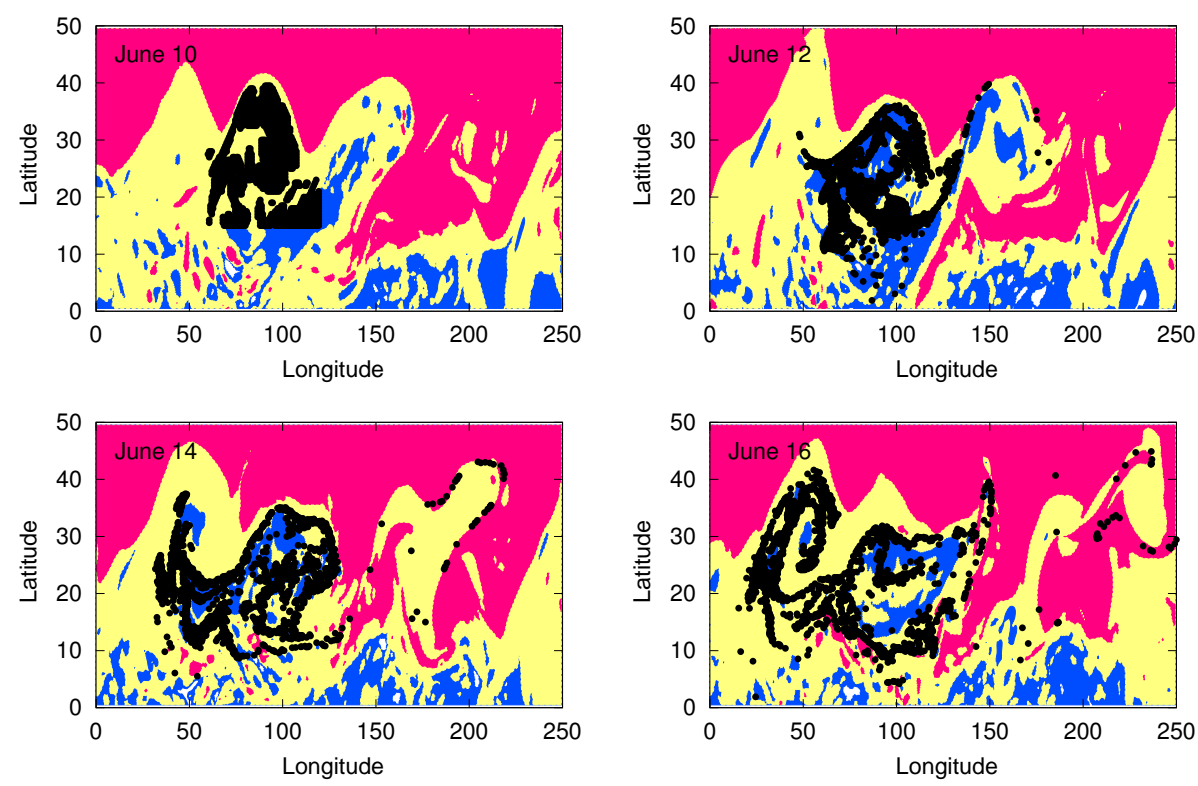

Figure 2. Example of isentropic trajectories on $360 \mathrm{~K}$, released on 10 June. Black dots highlight trajectory locations on 10 , 12 , 14 and 16 June, together with PV (red: > 2 PVU; blue: <0.3 PVU; yellow: intermediate).

\section{Confinement of the anticyclone on isentropic levels}

As a first step, we study the confinement of air within the anticyclone at isentropic levels. An example of trajectories in the first 6 days after their initialization within the anticyclone is shown in Fig. 2. Trajectories largely follow regions of low PV. A few trajectories are advected out of the anticyclone following the PV streamer that is shed from the anticyclone to the east. This shedding event from the anticyclone was found to be associated with elevated $\mathrm{CO}$ concentrations colocated with the PV streamer (see Fig. 10 of GR13). Thus, observed tracer anomalies, low PV as well as the trajectory calculations show a consistent picture of air being shed from the anticyclone. The trajectory calculations enable us to investigate the further transport of air that was shed from the anticyclone and the role of such shedding events over the season.

The mean horizontal distributions of trajectories after 10 , 20 and 30 days of their initialization are shown in Fig. 3 (bottom panels). The mean distributions are obtained by combining the distributions of all trajectories initialized each day between 1 June and 31 August of the year 2006. The distribution is given in percentage of the total number of trajectories, and in the following, percentage numbers mentioned in the text always refer to a fraction of the total number of trajectories.

Within the first 10 days, trajectories mostly remain within the anticyclone both at 360 and $380 \mathrm{~K}$. After 20 days, the likelihood of trajectories to be shed from the anticyclone to the east or west and also to the south increases. While the maximum of the distribution remains within the anticyclone after 30 days, trajectories are spread over the tropical belt, and a second maximum in the distribution is found in the Southern Hemisphere near $20^{\circ} \mathrm{S}$ (see Fig. 3, bottom right panel). No trajectories reach the southern extratropics (likely because the subtropical jet acts as a transport barrier), but a few $(3 \%)$ reach the northern extratropics after 30 days.

At higher altitudes $(380 \mathrm{~K})$, the anticyclone becomes more confined: the mean distributions of trajectories initialized within the anticyclone at the $380 \mathrm{~K}$ level after 10, 20 and 30 days are shown in Fig. 3 (top panels). After 30 days, trajectories are spread to the east and west of the anticyclone, but few trajectories reach the Southern Hemisphere. Thus, a single maximum in the latitudinal distribution is found at $380 \mathrm{~K}$ after 30 days (see Fig. 3, top right panel). However, more trajectories reach the northern extratropics $(8 \%$ of all trajectories) at $380 \mathrm{~K}$ compared to $360 \mathrm{~K}$.

The upper-tropospheric anticyclone has a distinct signature in tracers like $\mathrm{CO}$, which has near-surface sources (from combustion) and is transported upward by deep convection associated with the monsoon. While tracers are confined by the anticyclone, shedding events as shown in Fig. 2 cause transport out of the anticyclone. The mean distributions of trajectories 20-30 days after their initialization in the anticyclone closely resemble the time average $\mathrm{CO}$ distribution both at 360 and $380 \mathrm{~K}$ (Fig. 4). Both CO and the trajectory distribution show maxima between 20 and $110^{\circ} \mathrm{E}$ that are elongated in the longitudinal direction. Furthermore, at $360 \mathrm{~K}$ higher probabilities of trajectories spreading to the south of the anticyclone are colocated with elevated $\mathrm{CO}$ concentrations there. This suggests that the isentropic outflow of high$\mathrm{CO}$ air from the anticyclone might contribute to the distribution of $\mathrm{CO}$ in the tropical upper troposphere. 

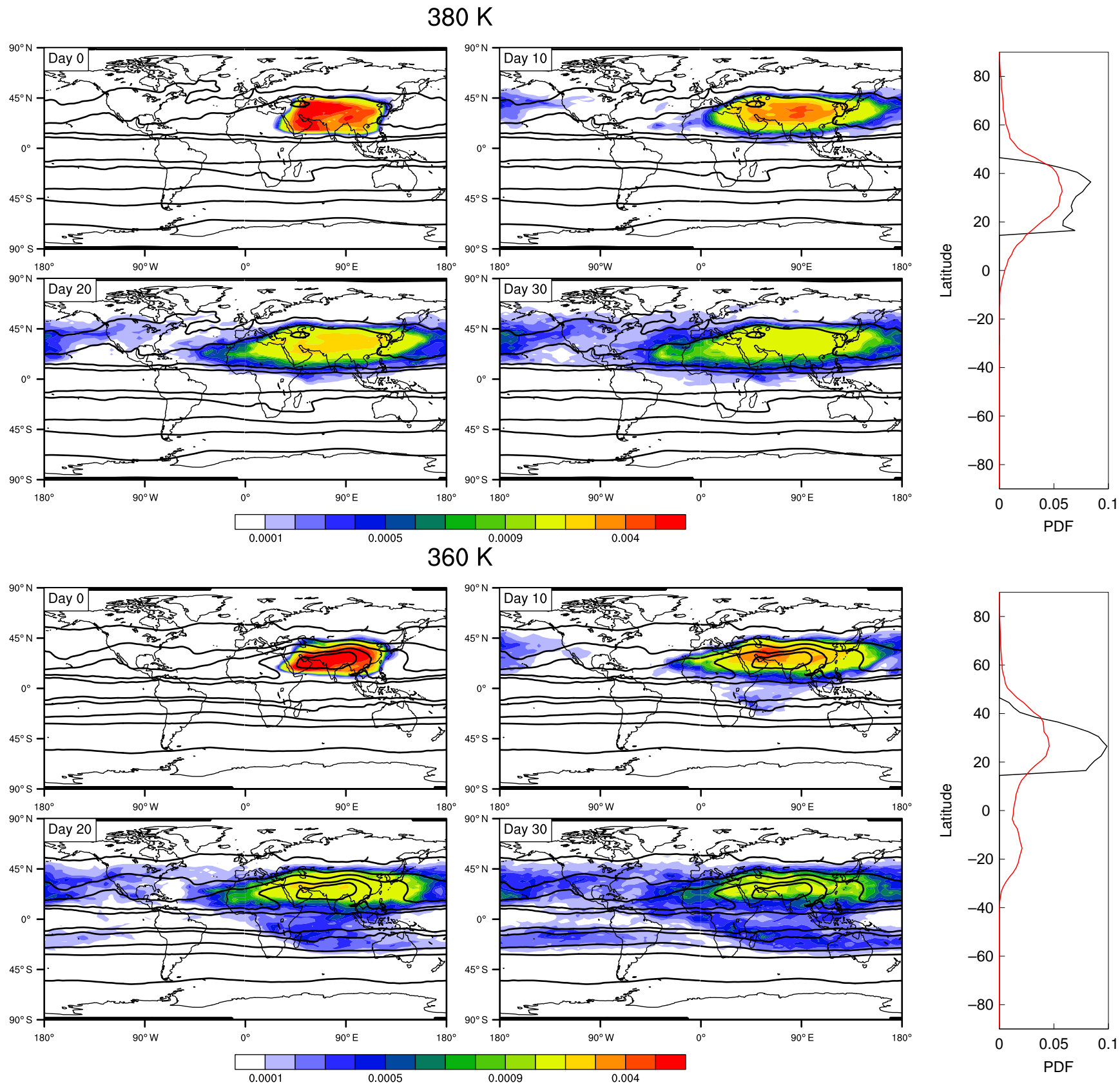

Figure 3. Mean JJA distribution of isentropic trajectories (in percentage of total number of trajectories) at the $380 \mathrm{~K}$ (top panels) and $360 \mathrm{~K}$ (bottom panels) level on day 0, 10, 20 and 30 after release, overlaid with mean JJA PV contours (at \pm 3 , 4, 6, 8 and 12 PVU at $380 \mathrm{~K}$ and $\pm 0.7,1,2,4$ and 8 PVU at $360 \mathrm{~K}$ ). Panels on the right show the zonal mean distribution on day 0 (black) and 30 (red).

\section{Transport from the anticyclone to the stratosphere}

Full three-dimensional transport of air parcels that originate in the upper-tropospheric anticyclone is investigated in the following. Trajectories are initialized at the $360 \mathrm{~K}$ level in the same fashion as the isentropic trajectories above (i.e., in regions of low PV). Trajectories are initialized each day from 1 June to 31 August and are run forward for 60 days.
An example of the temporal development of the latitudeheight distribution of trajectories over 60 days is shown in Fig. 5 for trajectories initialized on 10 June. The top row shows kinematic trajectories, the bottom row trajectories with identical initial positions but transported diabatically in the vertical. After the first 20 days, most trajectories are still confined to the Northern Hemisphere tropics but are spread in the vertical. A large fraction of the trajectories has moved 

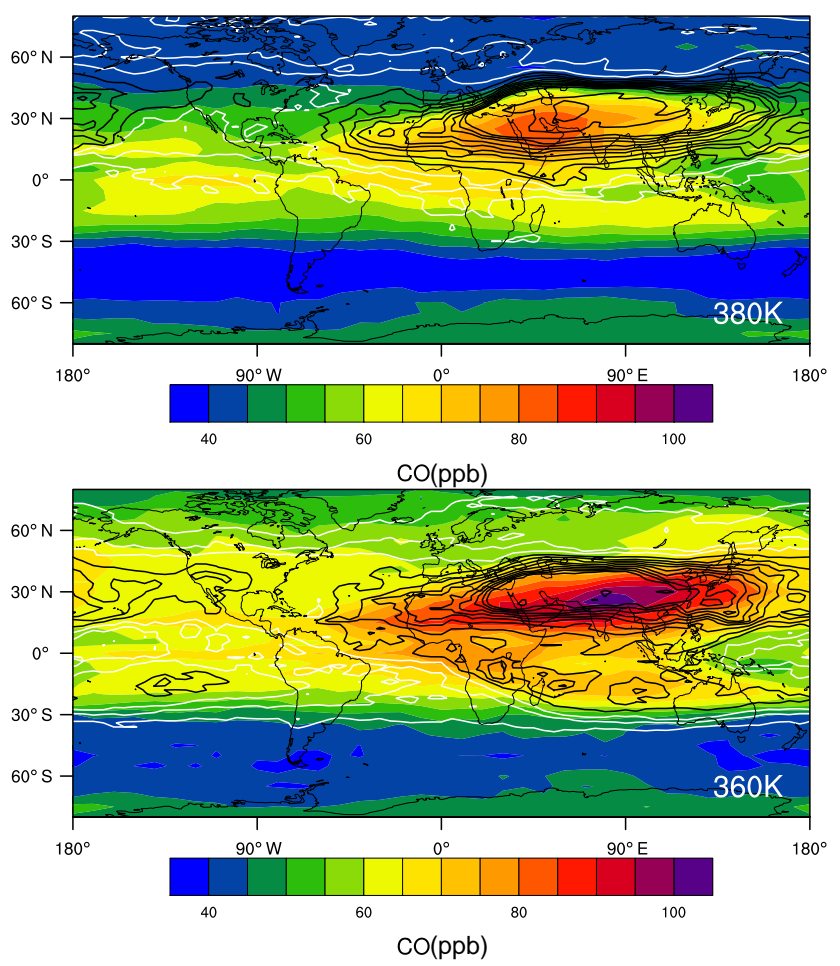

Figure 4. Mean JJA distribution of parcel locations averaged over day 20-30 (white: 0.02 to $0.07 \%$; black: 0.08 to $0.25 \%$ ) overlaid on mean JJA CO concentrations as measure by Microwave Limb Sounder (MLS) at $380 \mathrm{~K}$ (top panel) and $360 \mathrm{~K}$ (bottom panel).

upward to higher potential temperatures, and some trajectories have crossed the tropopause. The trajectories spread over the tropics and in the vertical as time progresses, including some systematic downward transport. The distributions are similar overall for kinematic and the diabatic calculations, but the trajectories are more dispersed vertically in the kinematic calculations.

\subsection{Probability distribution functions and transport timescales}

The mean probability distribution functions (PDFs) averaged over all trajectories released each day between 1 June to 31 August are shown in Fig. 6 for kinematic and for diabatic calculation of vertical transport. After 20 days, the maximum in the PDF lies above the mean $360 \mathrm{~K}$ level, and trajectories spread slightly over the tropics. A considerable fraction of air parcels move downward, and for diabatic transport a second maximum is found around $400-500 \mathrm{hPa}$. After 60 days, the maximum in the PDF is found above the tropical tropopause. The maximum is stronger and more confined for diabatic transport, while trajectories are more widely spread over the tropical troposphere and lower stratosphere for kinematic calculations. This behavior can be seen more clearly in the PDF of trajectories with respect to potential temperature (Fig. 7): diabatic trajectories show two distinct maxima after
60 days; one is formed by trajectories that traveled upward (at 390-400 K) and one by trajectories that traveled downward (at 320-330 K). Kinematic trajectories, on the other hand, show a broader distribution that maximizes in the lower troposphere at 320-330 K. Overall, the diabatic calculations result in more trajectories traveling to higher levels that lie well above the tropopause.

To understand the causes for the vertical spread in the trajectories, Fig. 8 shows the mean vertical velocities (top panel) and diabatic heating rates $\mathrm{d} \Theta / \mathrm{d} t$ (bottom panel) at the $360 \mathrm{~K}$ level (i.e., the level where trajectories are initialized). Strong positive heating rates are found in regions of low OLR, namely over the Bay of Bengal and the western Pacific Ocean north of Indonesia. The upward vertical velocities are located further away from the Equator and are overall patchier, even in the monthly mean. While the distributions differ in many respects, both vertical velocities and diabatic heating rates show mean upward transport in the eastern part of the anticyclone but downward transport in the western part. This explains why trajectories released in the anticyclone travel both upward and downward.

The transit time distributions for parcels traveling upward to the 380 and the $400 \mathrm{~K}$ levels is shown in Fig. 9. The most likely time it takes an air parcel from its initial level at 360 to $380 \mathrm{~K}$ is around 15 to 20 days. To reach the $400 \mathrm{~K}$ level, an air parcels travels 30 to 40 days in the mean. These transit times are faster compared to those estimated by Ploeger et al. (2010) of around 15-20 days/10 K, but this difference may be explained by their focus on the entire tropics compared to our focus on the anticyclone. At both 380 and $400 \mathrm{~K}$, the transit time distributions peak earlier for kinematic transport, but larger fractions of trajectories reach those levels for diabatic transport. This further illustrates the dispersive nature of kinematic calculations. Overall, it can be concluded that diabatic upward transport is stronger and more persistent, while kinematic results are more diffusive and weaker in the mean.

\subsection{Transport pathways}

To quantify the destination of parcels originating from the monsoon anticyclone, we subdivide the atmosphere into nine regions, and the fraction of trajectories located in each of those regions after 30 and 60 days of integration is given in Table 1. The tropopause is defined here as the thermal tropopause (according to the WMO definition), and daily data of tropopause height are used to assign each particle at each time step to the stratospheric or tropospheric region. With this definition of cross-tropopause transport, short-term fluctuations across the tropopause are included, but tests including residence time criteria showed that this does not affect the conclusions of this study. The locations of tropopause crossings (shown in Fig. 11) are, however, limited to crossings where the trajectory remains 5 days in the troposphere prior to the crossing and 5 days in the stratosphere after the 

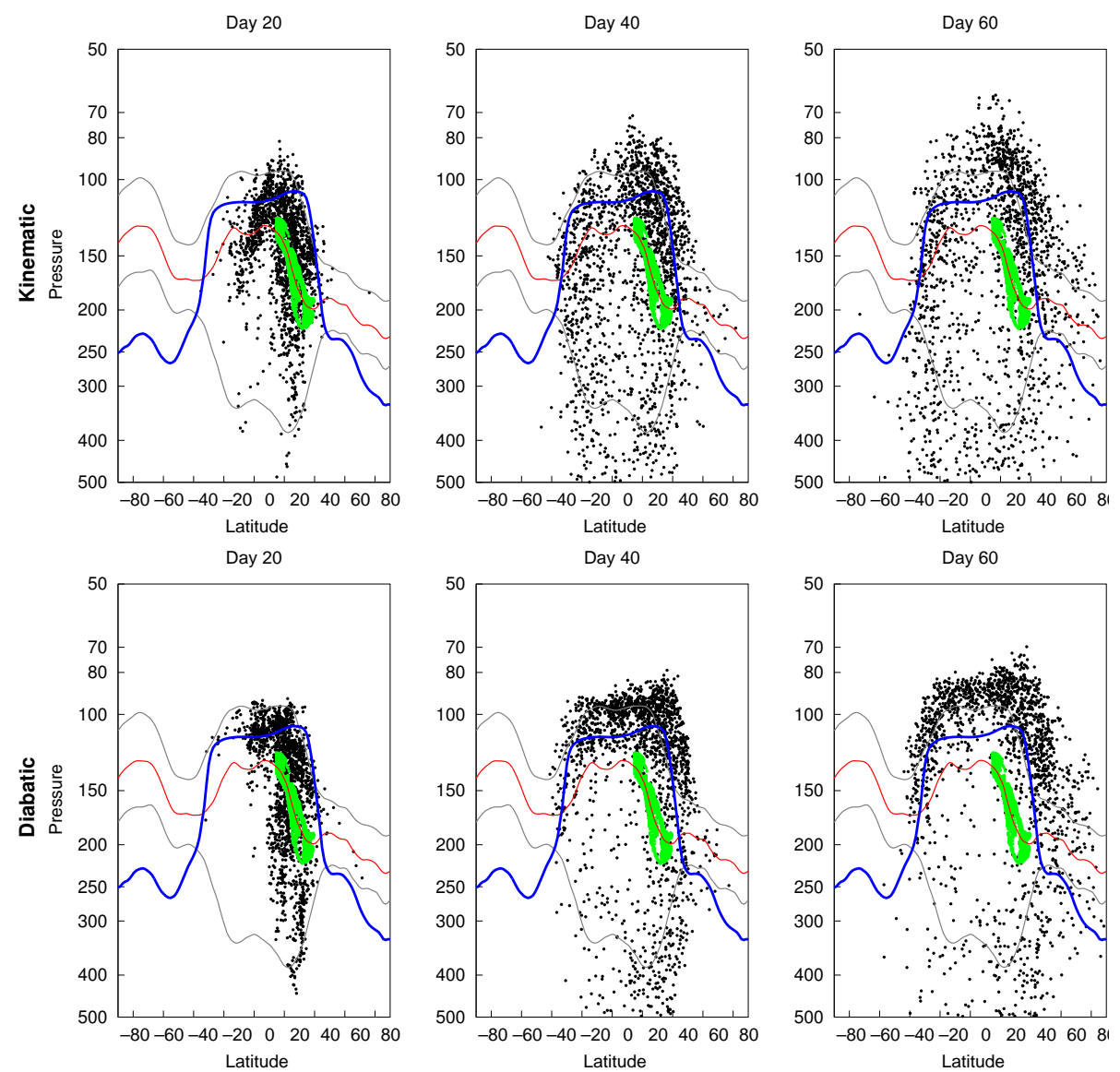

Figure 5. Trajectories released within the anticyclone at $360 \mathrm{~K}$ on 10 June after 20, 40 and 60 days for kinematic (top panels) and diabatic (bottom panels) calculation of vertical transport. Green dots mark the initial location. The blue line is the mean thermal tropopause at $20-120^{\circ} \mathrm{E}$, the red line the mean $360 \mathrm{~K}$ isentrope and the gray lines the 340 and $380 \mathrm{~K}$ isentropes.

crossing. This limitation sharpens the geographical distribution but does not significantly differ from the pattern of the distribution of all crossings. The latitudinal boundaries of the defined regions (see Table 1) are chosen to approximately match the locations of the transport barriers, i.e., jets (see, e.g., Figs. 1, 3 and 14).

The time series for the most important regions are shown in Fig. 10. Within the first 10 days, few trajectories enter the stratosphere, but after 30 days $21 \%$ (35\%) of the trajectories entered the lower stratosphere for kinematic (diabatic) calculations, and after 60 days $31 \%(48 \%)$ are located in the stratosphere. Most of the trajectories that entered the stratosphere are located within the tropics $(21 \% / 32 \%$ of all trajectories after 60 days) but only about a third of those in the region of the anticyclone (see Table 1). Eight percent ( $15 \%$ ) of all trajectories are located in the northern extratropical stratosphere after 60 days, mostly entering this region after 30 days (see green curve in Fig. 10). The transit time distribution to the stratosphere (lower panel of Fig. 10) maximizes at transit times of around 10-15 days. As shown in Fig. 11, the most likely geographical entry point of trajectories to the strato- sphere is located over the Bay of Bengal and to the east of the anticyclone, for both kinematic and diabatic calculations. This is consistent with upward transport velocities in this region (Fig. 8).

Of those trajectories that do not travel upward and into the stratosphere, most descend to levels below $250 \mathrm{hPa}$ (46 and $39 \%$ after 60 days). For both diabatic and kinematic transport, most of those trajectories descend within the first 10 days.

Both the fraction of trajectories that travel to the stratosphere and those that are transported downward are relatively constant after about 40-50 days (see Fig. 10). Therefore, it can be concluded that timescales of transport processes as examined here are well captured by the 60-day duration of the trajectories.

The destinations of trajectories that originate from the anticyclone that are discussed above give no information about the pathways the trajectories take to the respective region. Trajectories do not travel necessarily directly from the uppertropospheric anticyclone to the destination region. For example, while $15 \%$ of all trajectories end up in the northern ex- 
Table 1. Fraction of trajectories located in different regions of the atmosphere after 30 and 60 days for kinematic/diabatic transport.

\begin{tabular}{llll}
\hline & 30 days & 60 days & Definition \\
\hline AC UT & $19 \% / 11 \%$ & $4 \% / 1 \%$ & $0-45^{\circ} \mathrm{N}, 45-180^{\circ} \mathrm{E}, 250 \mathrm{hPa}$ to tropopause \\
AC LS & $7 \% / 13 \%$ & $6 \% / 8 \%$ & $0-45^{\circ} \mathrm{N}, 45-180^{\circ} \mathrm{E}$, above tropopause \\
Trop UT & $28 \% / 17 \%$ & $15 \% / 6 \%$ & $30^{\circ} \mathrm{S}-45^{\circ} \mathrm{N}$ but not AC, 250 hPa to tropopause \\
Trop LS & $11 \% / 18 \%$ & $15 \% / 24 \%$ & $30^{\circ} \mathrm{S}-45^{\circ} \mathrm{N}$ but not AC, above tropopause \\
ExTR NH UT & $3 \% / 3 \%$ & $3 \% / 3 \%$ & $45-90^{\circ} \mathrm{N}, 250 \mathrm{hPa}$ to tropopause \\
ExTR SH UT & $1 \% / 0 \%$ & $2 \% / 1 \%$ & $90-30^{\circ} \mathrm{S}, 250 \mathrm{hPa}$ to tropopause \\
ExTR NH LS & $3 \% / 4 \%$ & $8 \% / 15 \%$ & $45-90^{\circ} \mathrm{N}$, above tropopause \\
ExTR SH LS & $0 \% / 0 \%$ & $1 \% / 3 \%$ & $90-30^{\circ} \mathrm{S}$, above tropopause \\
$>250 \mathrm{hPa}$ & $28 \% / 34 \%$ & $46 \% / 39 \%$ & below $250 \mathrm{hPa}$ \\
\hline
\end{tabular}
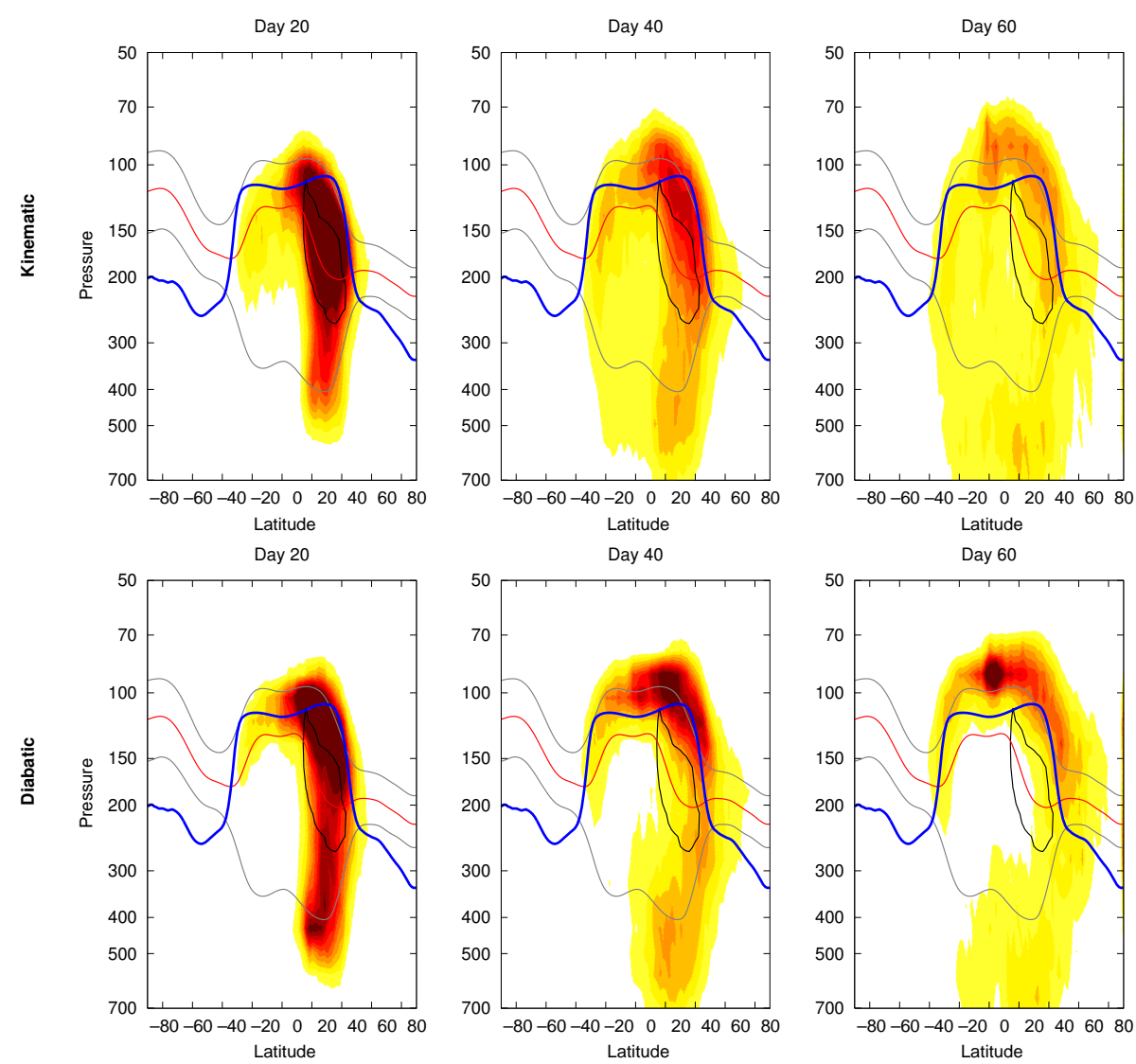

Figure 6. Mean distribution of three-dimensional kinematic trajectories (top panels) and three-dimensional diabatic trajectories (bottom panels) released within the anticyclone at $360 \mathrm{~K}$ on day 20, 40 and 60 after their release given as fraction of total number of trajectories (dark $\left(5 \times 10^{-3}\right)$ to light yellow $\left.\left(5 \times 10^{-4}\right)\right)$. The black contour indicates the initial distribution of trajectories, and the dark blue line is the mean thermal tropopause between $20-120^{\circ} \mathrm{E}$. The red line is the mean location of the $360 \mathrm{~K}$ level in $45-120^{\circ} \mathrm{E}$, and the gray lines are the 340 and $380 \mathrm{~K}$ isentropes.

tratropical stratosphere after 60 days, they are not necessarily transported there directly from the upper-tropospheric anticyclone via isentropic transport. Therefore, we discuss the pathways of trajectories from the upper-tropospheric anticyclone to the three most important destinations (tropical lower stratosphere (LS), northern extratropical LS and lower troposphere) in more detail in the following. While we discuss pathways for diabatic transport in the following, the relative importance of the different pathways for kinematic transport are qualitatively the same.

\subsubsection{Transport to the tropical lower stratosphere}

To highlight the pathways to and from the tropical lower stratosphere, total air parcel fluxes over 60 days to and from 

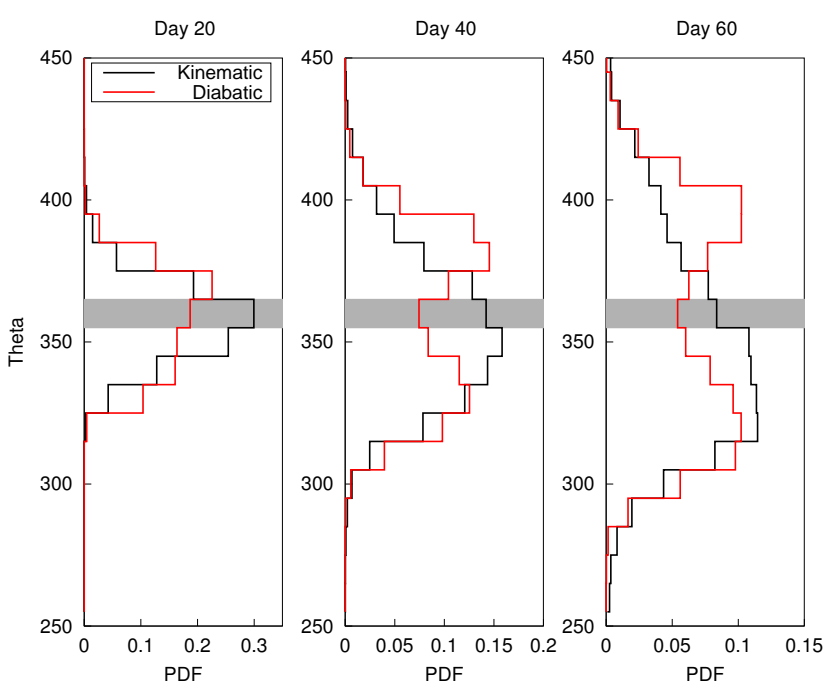

Figure 7. Mean distribution of trajectories with respect to potential temperature for kinematic (black) and diabatic (red) transport. The gray bar denotes the initial location.
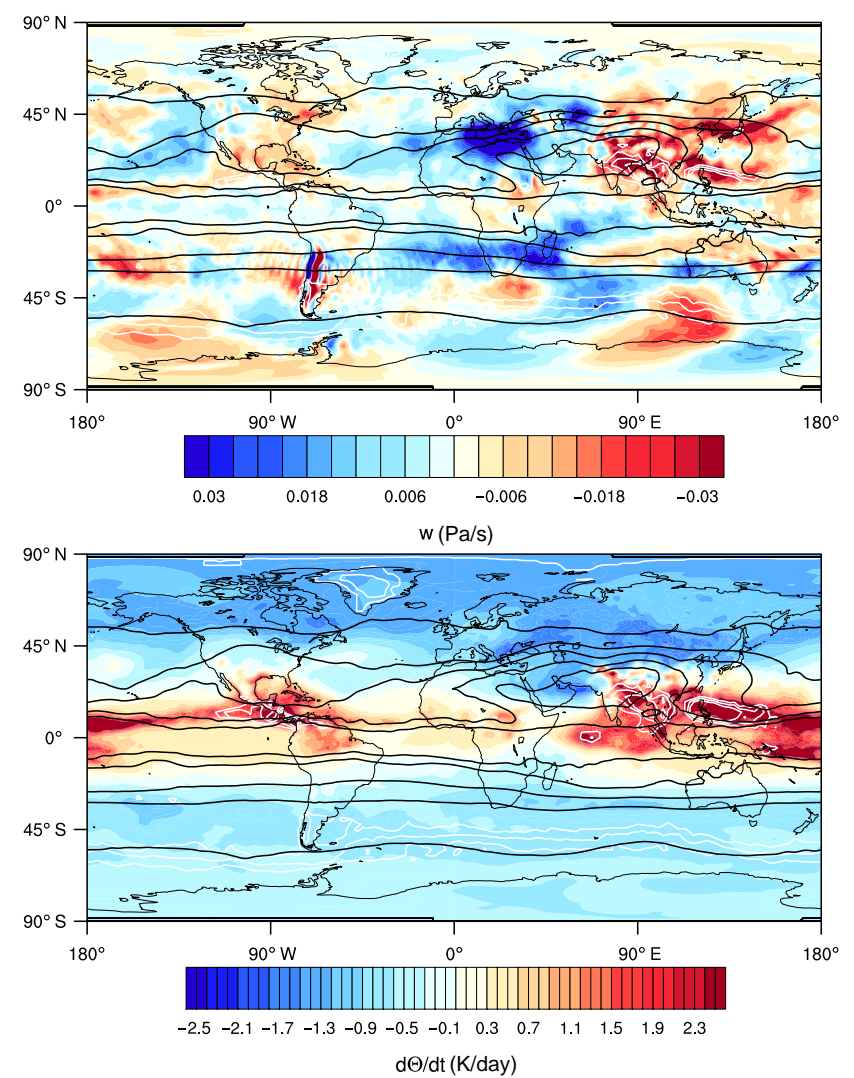

Figure 8. Monthly mean vertical velocity (top panel, in pascal per second; note the flipped color bar) and $\mathrm{d} \Theta / \mathrm{d} t$ (bottom panel, in kelvin per day) at $360 \mathrm{~K}$ together with PV (black contours, for \pm 8 , 4, 2, 1 and 0.7 PVU) and OLR (white contours, at 190, 200 and $210 \mathrm{~W} \mathrm{~m}^{-2}$ ) for July 2006.
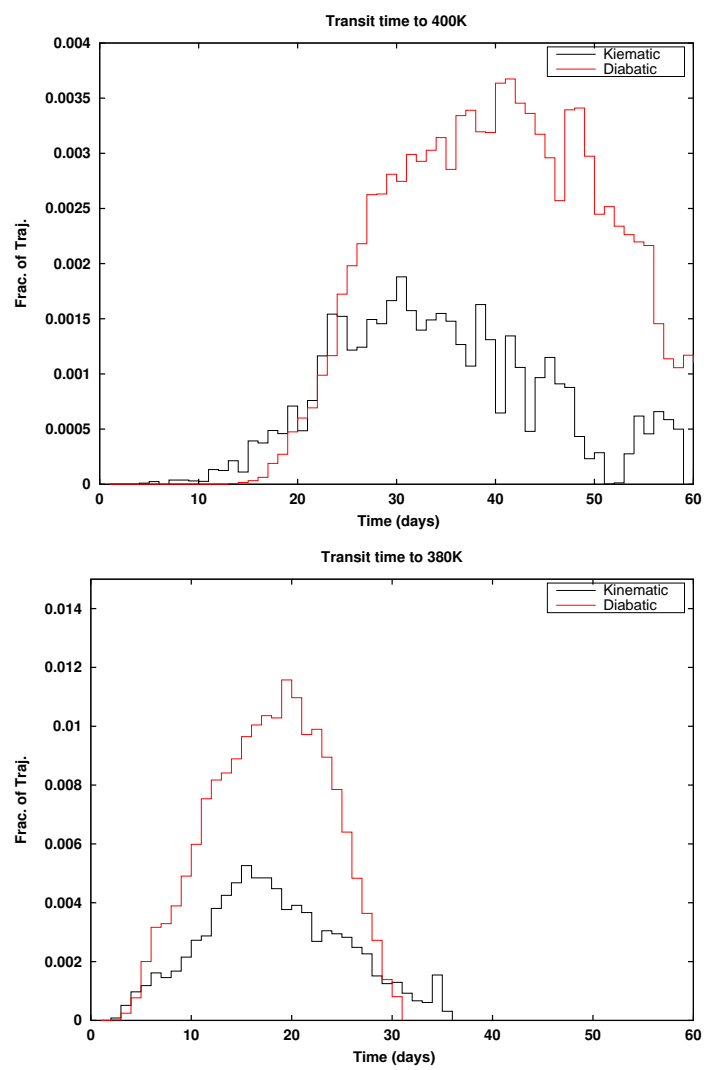

Figure 9. Transit time distribution from 360 to $380 \mathrm{~K}$ (top panel) and to $400 \mathrm{~K}$ (bottom panel) for diabatic (red) and kinematic (black) trajectories.
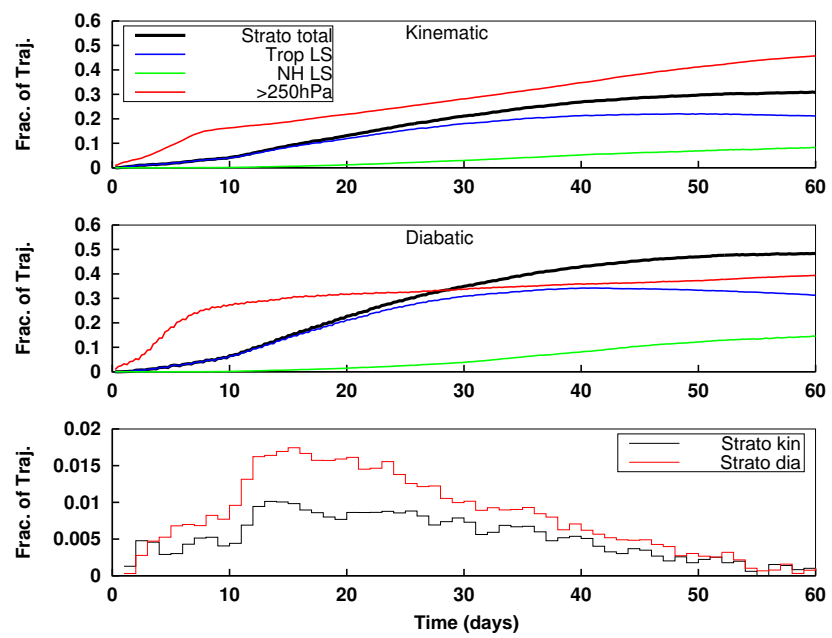

Figure 10. Fraction of trajectories located in the stratosphere (black), the tropical stratosphere only (blue), the northern extratropical stratosphere (green) and below $250 \mathrm{hPa}$ (red) as a function of time for kinematic (top panel) and diabatic (middle panel) transport. Bottom panel: transit time distribution to the stratosphere.

this region are shown in Fig. 12a. The numbers are obtained by counting all trajectories that enter or leave the specific 

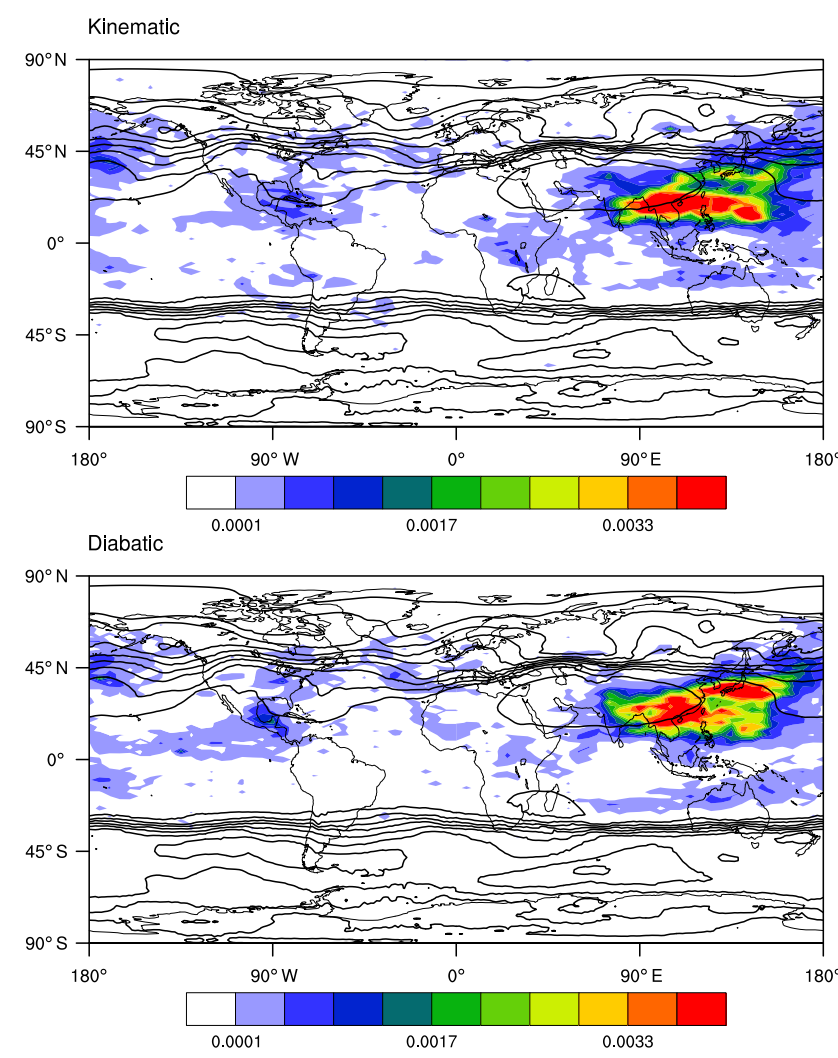

Figure 11. Geographical distribution of locations of tropopause crossings (as fraction of all trajectories; top panel: kinematic; bottom panel: diabatic) and contours of thermal tropopause height (black; contours between 110 and $290 \mathrm{hPa}$ with interval $20 \mathrm{hPa}$ ). In order to exclude short-term reversible events, results here only include parcels remaining in the troposphere 5 days before and in the stratosphere 5 days after crossing the tropopause.

region within the 60 days via the different pathways, and percentages are the fraction of the total number of trajectories initially released in the anticyclone. The budget analysis shows that the preferred pathway of trajectories is to travel from within the upper-tropospheric anticyclone region to the tropical lower stratosphere (32\% of all trajectories). Another $14 \%$ are first mixed outside of the anticyclone into the tropical upper troposphere and are subsequently transported upward into the tropical lower stratosphere. From the tropical lower stratosphere, some trajectories (14\% of all trajectories) are further transported to the extratropical stratosphere, the majority $(12 \%)$ to the north. Thus, of the $46 \%$ transported into the tropical lower stratosphere, only $32 \%$ remain here after 60 days.

\subsubsection{Transport to the northern extratropical stratosphere}

A total of $15 \%$ of all trajectories is located in the northern extratropical lower stratosphere after 60 days. However, as revealed by the budget for this region (Fig. 12b), most (a)

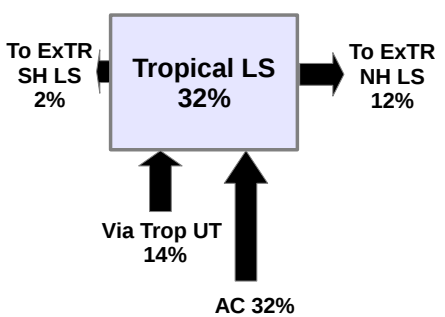

(b)

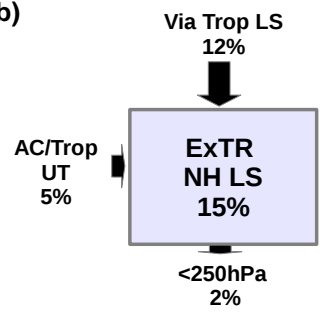

Figure 12. Total air parcel fluxes over 60 days (in percentage of total number of trajectories) into and out of (a) the tropical lower stratosphere and (b) the northern extratropical lower stratosphere. The numbers in the boxes are the fraction of trajectories that remain in the region after 60 days.

of those trajectories do not travel directly from the uppertropospheric anticyclone to the northern extratropical stratosphere: the most common pathway is via upward transport into the tropical stratosphere and subsequent transport to the northern extratropics ( $12 \%$ of all trajectories). Far fewer trajectories (5\% of all trajectories) were transported there directly from the tropical upper troposphere, likely by mixing of tropical and extratropical air masses. With a total of $2 \%$ of all trajectories leaving the extratropical lower stratosphere to the troposphere below, $15 \%$ remain here after 60 days. Thus, the pathway via the tropics with slow vertical motion dominates over the pathway by fast isentropic mixing for air to be transported from the upper-tropospheric anticyclone to the northern extratropical stratosphere. This is consistent with transport times of 30 days or more for most air parcels to reach the extratropical stratosphere (see green curve in Fig. 10).

\subsubsection{Downward transport to the middle troposphere}

The distribution of trajectories that are transported downward to below $250 \mathrm{hPa}$ has a maximum over the Middle East (Fig. 13), likely caused by the downward velocities over this region (see Fig. 8). The downward transport is strong in particular during July, in line with strong negative heating rates over the western part of the anticyclone during the same time period (not shown). Li et al. (2001) and Liu et al. (2009) discussed a local ozone maximum over the Middle East in the middle troposphere (around 400 to $500 \mathrm{hPa}$ ), and they show that this ozone anomaly is caused by a combination of local ozone production and by transport of ozone from Asia (Liu et al., 2011). The distribution of trajectories that are transported downward from the Asian monsoon anticyclone resembles the ozone anomaly in the Middle East (see Fig. 1 of Liu et al., 2009) and is similar to the contribution of ozone produced in the upper troposphere over Asia (see Fig. 9b of Liu et al., 2009). Liu et al. (2009) suggest that this uppertropospheric production of ozone over Asia is linked to the generation of $\mathrm{NO}_{x}$ from lightning, which occurs in the region 


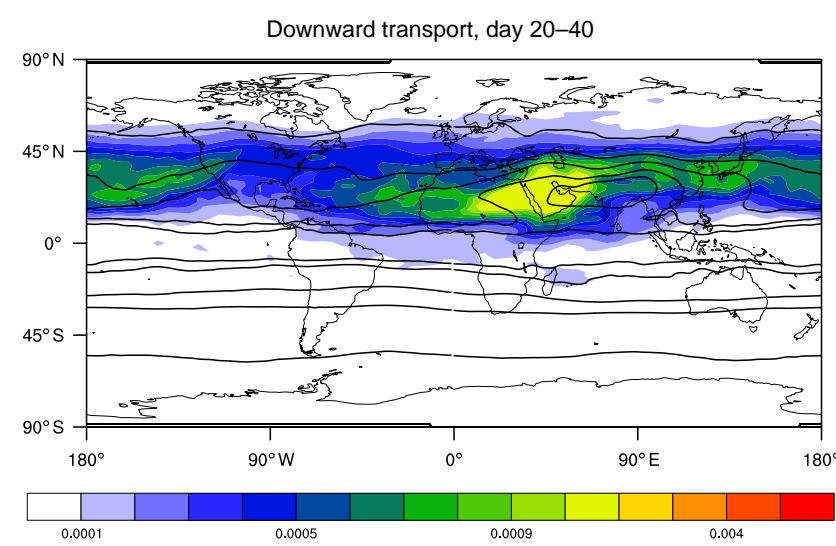

Figure 13. Mean JJA distribution of diabatic trajectories (in percentage of total number of trajectories) that are transported downward (to $>250 \mathrm{hPa}$ ) averaged over day 20 to 40 after their release in the anticyclone at $360 \mathrm{~K}$, overlaid with mean JJA PV (contours at $\pm 0.7,1,2,4$ and 8 PVU).

of deep convection. Therefore, we speculate that the persistent downward transport of air from within the anticyclone, and thus from the region of convective outflow, might contribute to the buildup of ozone in the middle troposphere over the Middle East.

\subsubsection{Summary of pathways}

The different transport pathways from the uppertropospheric anticyclone (at $360 \mathrm{~K}$ ) to the stratosphere are summarized in Fig. 14. The most likely pathway for trajectories initialized in the upper-tropospheric anticyclone is to travel upward within the anticyclone and enter the stratosphere in the northern (sub-)tropics, in particular in the southeastern part of the anticyclone. Another smaller fraction of trajectories is first transported into the tropical upper troposphere and transported upward from there. Fewer trajectories are transported from the anticyclone to the extratropical lower stratosphere, and only a very small number of those are transported directly from the anticyclone to the extratropical lower stratosphere, likely by isentropic mixing. Trajectories that are located in the extratropical stratosphere after 60 days more likely traveled there via upward transport into the tropical stratosphere and subsequent mixing to the northern extratropics.

\section{Trajectories with realistic sources and broad vertical distributions}

So far, we have analyzed air parcels that were initialized in the upper-tropospheric anticyclone at $360 \mathrm{~K}$. However, deep convection might not lift air parcels as high as $360 \mathrm{~K}$. The profile of mean divergence suggests maximum outflow at levels around 340 to $370 \mathrm{~K}$ (Fig. 1). Furthermore, the geo-

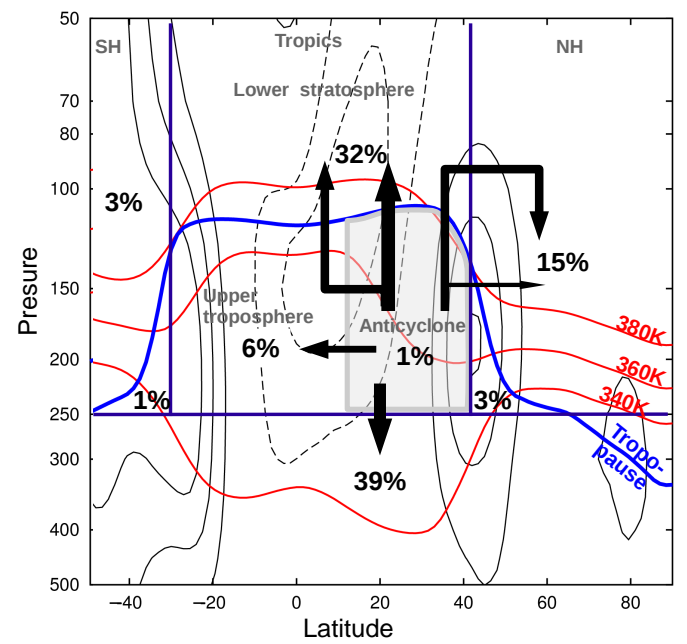

Figure 14. Schematic of the most prominent transport pathways of air originating in the upper-tropospheric anticyclone around $360 \mathrm{~K}$ (gray box). Numbers indicate fraction of trajectories (in percentage) that are located in the respective regions after 60 days for diabatic transport. The width of the arrows reflects the importance of the respective pathway. Contours show the zonal mean wind (black solid: positive; black dashed: negative), the tropopause (blue) and the 340 , 360 and $380 \mathrm{~K}$ isentrope (red) averaged over $20-120^{\circ} \mathrm{E}$.

graphical location of air parcels that were lifted upward by deep convection is not equivalent to the region of the anticyclone. Therefore, we investigate in the following the distributions of air parcels that are located initially in regions of low OLR (specifically, OLR $<160 \mathrm{Wm}^{-2}$, as a proxy for deep convection) at different altitudes between 340 to $380 \mathrm{~K}$. We conduct these sensitivities using diabatic transport. As will be discussed in Sect. 6, there is little difference found between the distribution of trajectories initialized at $360 \mathrm{~K}$ within the anticyclone (regions of low PV), as investigated so far in this paper, and the distribution of trajectories initialized at $360 \mathrm{~K}$ within regions of low OLR.

Figure 15 compares the distribution of trajectories with respect to potential temperature after 60 days for different initial heights between 340 to $380 \mathrm{~K}$. A clear separation of air parcels is found after 60 days: while air parcels that were initialized below $360 \mathrm{~K}$ most likely descend within the 2 months after initialization to potential temperature levels around 300 to $330 \mathrm{~K}$, air parcels that are initialized above $360 \mathrm{~K}$ most likely rise to potential temperature levels of $380 \mathrm{~K}$ and above. The $360 \mathrm{~K}$ level appears to act as a boundary between rising and sinking parcels. Consequently, only less than $15 \%$ of the trajectories initialized at $350 \mathrm{~K}$ or below reaches the stratosphere, while about $50 \%$ of those initialized at $360 \mathrm{~K}$ and more than $90 \%$ of those initialized at $370 \mathrm{~K}$ or above reach the stratosphere. At all levels, the dominant pathway to the stratosphere is upward advection to the tropical stratosphere, while isentropic transport to the extratropical lower stratosphere is of minor importance. 

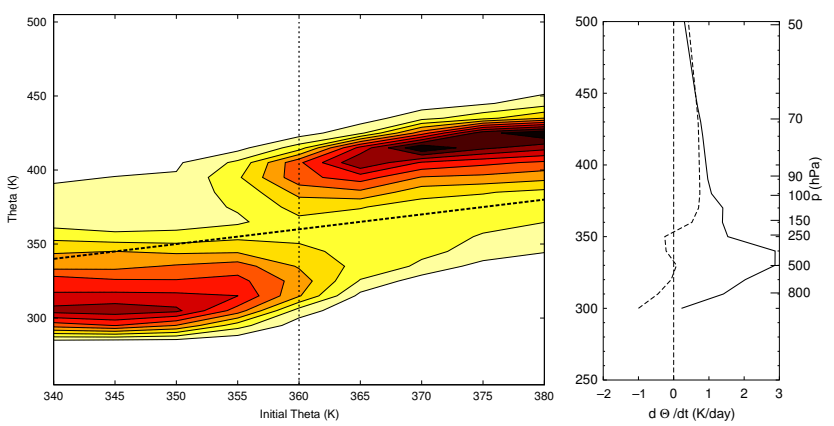

Figure 15. Left panel: distribution of diabatic trajectories in potential temperature initiated between 340 to $380 \mathrm{~K}$ ( $x$ axis) in regions of low OLR $\left(\leq 160 \mathrm{~W} \mathrm{~m}^{-2}\right)$ after 60 days. The thick black dashed line indicates the level of initialization. Right: mean JJA 2006 profile of $\mathrm{d} \Theta / \mathrm{d} t$ averaged over $60-120^{\circ} \mathrm{E}$ and $0-30^{\circ} \mathrm{N}$ (solid) and over the entire tropical belt, $30^{\circ} \mathrm{S}-30^{\circ} \mathrm{N}$ (dashed).

The mean profile of diabatic heating in the anticyclone region suggests that air is lifted in the mean throughout the atmosphere, and that lifting is strongest at $330-340 \mathrm{~K}$ (see Fig. 15, right panel). This seems to contradict the finding that air parcels initialized below $360 \mathrm{~K}$ are more likely descending to lower levels. However, in order to be lifted by the positive vertical winds air parcels need to be confined to the region of lifting, i.e., the anticyclone region. Heating rates are close to or less than zero at levels below $355 \mathrm{~K}$ in the tropical mean (see dashed line in Fig. 15, right panel). As shown in Fig. 16 the fraction of air parcels that remains in the initial anticyclone region (here defined as $0-45^{\circ} \mathrm{N}, 0$ $180^{\circ}$ E) quickly drops to below $20 \%$ after about 10 days for trajectories initialized below $360 \mathrm{~K}$, while those initialized above are more likely to remain in the anticyclone region. As was shown in the last section, most trajectories initialized at $360 \mathrm{~K}$ are lifted upward and into the stratosphere within 1020 days after their initialization, and the most likely pathway is through the anticyclone region. Below $360 \mathrm{~K}$ the anticyclone appears not to be strong enough to confine air in the region of ascent, and thus it is transported away and descends elsewhere.

Overall, these results suggest that air parcels need to be lifted by deep convection to levels around $360 \mathrm{~K}$ or above in order to be likely transported further upward and into the stratosphere. It is well known that parcels need to be lifted to a certain height threshold (commonly thought of as the level of zero radiative heating) to travel further upward into the stratosphere (e.g., Fueglistaler et al., 2009; Gettelman et al., 2004). Since diabatic heating rates are positive essentially at all heights in the anticyclone region according to ERAInterim (see Fig. 15, right panel) one might assume that the injection height is no limitation for upward transport here. However, it turns out that the horizontal confinement to the anticyclone region is the limiting factor here: the confinement is given only at or above $360 \mathrm{~K}$; thus, the injection

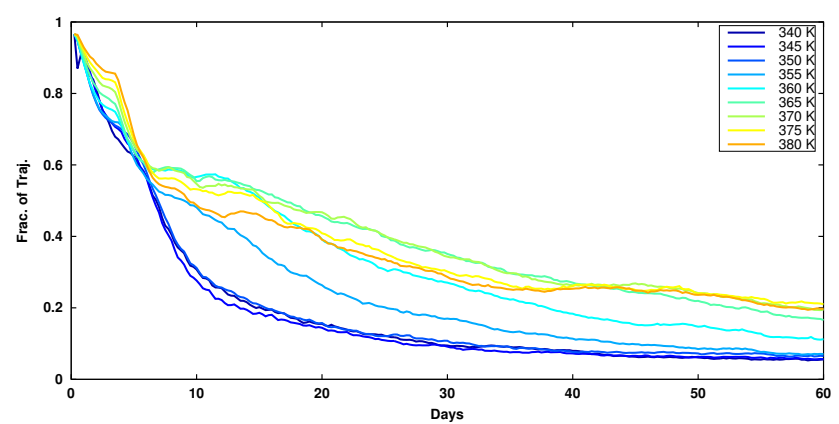

Figure 16. Fraction of diabatic trajectories that remain in the anticyclone region as a function of time after initialization for different initial potential temperature levels (see legend).

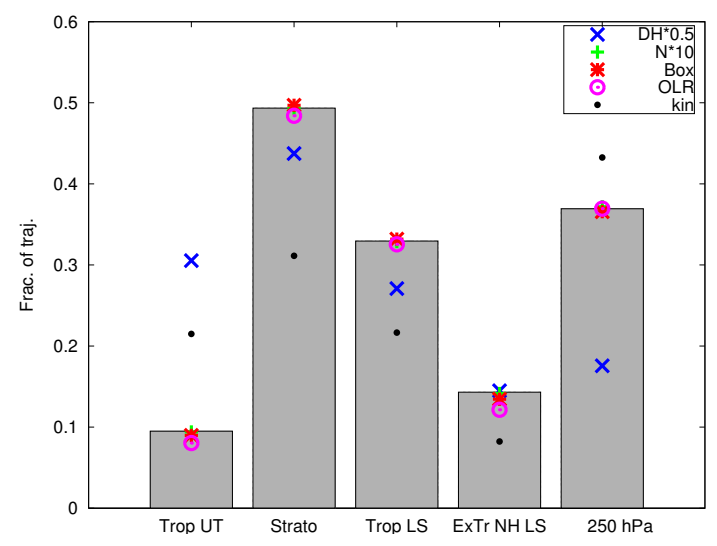

Figure 17. Fraction of trajectories located in the indicated regions ( $x$ axis) averaged over day 50-60 for a subset of 10 initial starting days between June and August. Shown are results from calculations with diabatic transport (gray bars), kinematic transport (black dot), diabatic heating rates scaled by 0.5 (blue $\mathrm{x}$ ), number of trajectories increased by a factor of 10 (green cross), initial positions in a box region (red star) and initial positions in low OLR regions (magenta circle).

height necessary for upward motion in the anticyclone turns out to be similar to the level of zero (diabatic) heating in the entire tropics, albeit for different reasons. The role of dynamical horizontal systems, in particular the anticyclone, in confining parcels to regions of upward motion was already pointed out by Bergman et al. (2012).

\section{Sources of uncertainties}

Several sources of uncertainties affect the trajectory calculations presented here. We performed sensitivity simulations to test the robustness of our results. The sensitivity simulations are performed for a limited number of initial days (10 days spaced evenly over the 3-month period June to August). Results of the sensitivity calculations, described in detail below, are shown in Fig. 17. 


\subsection{Trajectory setup}

To test the sensitivity of our results to the exact setup of initial trajectory positions, we performed additional calculations with trajectories initialized in a box region from 15 to $45^{\circ} \mathrm{N}$ and 20 to $130^{\circ} \mathrm{E}$. Another sensitivity is given by the calculations with initial positions at $360 \mathrm{~K}$ in region of low OLR (see Sect. 5). The mean initial distribution of trajectories initiated in regions of low OLR lies further southward (centered over India and the Indian ocean) compared to those initiated in regions of low PV. Furthermore, a total of 1000-2000 trajectories released each day might be considered too small a number given the length of the trajectories of 60 days. We increased the number of trajectories by a factor of 10 , distributing the additional trajectories randomly in each latitude-longitude box that previously contained one individual trajectory. As can be seen in Fig. 17, the final (day 50-60) destinations of trajectories are very robust against the number of trajectories released and initial positions. Within the first 10-20 days, some differences occur for the different setups of initial positions. For example, trajectories initialized in regions of low OLR are slightly more likely to rise within the first 20 days. However, overall the conclusions of this study are unaffected by the exact setup of trajectory initialization.

\subsection{Vertical velocities}

Vertical velocities that are crucial to three-dimensional trajectory modeling underlie two sources of uncertainty: biases of the data set used and uncertainties in the calculation of vertical advection (e.g., Ploeger et al., 2010). While the ERAInterim reanalysis data that our study is based on are generally improved compared to earlier reanalysis products (Dee et al., 2011), uncertainties and biases remain. Diabatic heating fields are significantly different among reanalyses. ERAInterim exhibits comparably strong diabatic heating rates in the tropics above $150 \mathrm{hPa}$ (Randel and Jensen, 2013; Wright and Fueglistaler, 2013), in particular in the region of the anticyclone, where convective processes strongly contribute to total diabatic heating (Wright and Fueglistaler, 2013). Furthermore, tropical upwelling in the lower stratosphere was found to be overestimated by $30-40 \%$ in ERA-Interim in previous studies (Schoeberl et al., 2012; Ploeger et al., 2012). To evaluate the impact of this bias on our results, we performed a sensitivity simulation in which we simply scaled diabatic heating rates by a factor of 0.5 . This crude scaling does of course not evaluate the full three-dimensional biases in the data (which are not known) but gives an idea of the impact of a bias towards too strong heating rates on our results. As expected, fewer trajectories reach the stratosphere and fewer are transported downward with these weaker heating rates, and more remain in the upper troposphere (see Fig. 17, blue $\mathrm{x}$ ). However, the fraction of trajectories transported to the stratosphere is affected by this crude scaling of heating rates less strongly than by the method of vertical velocity calculations (i.e., kinematic versus diabatic). We used both reanalysis vertical velocities and total heating rates throughout the paper to test the sensitivity of our results to uncertainties in vertical transport. While we find shorter transit times from $360 \mathrm{~K}$ to isentropic levels above (380 and $400 \mathrm{~K}$ ) for kinematic transport in agreement with Ploeger et al. (2010), overall diabatic transport is found to be more persistent and thus a larger fraction of trajectories reaches the stratosphere for diabatic compared to kinematic transport. While exact numbers of trajectories transported to different regions differ, overall our results regarding the relative role of different transport pathways are not sensitive to the method of vertical transport calculations.

\section{Discussion and summary}

Transport pathways of air from within the upper-tropospheric Asian monsoon anticyclone have been investigated using trajectory calculations driven by ERA-Interim reanalysis winds and diabatic heating fields. Efficient transport from the surface to the upper-tropospheric anticyclone is indicated by observations of tracer anomalies in this region, with maxima in tracer concentrations of tropospheric origin (like $\mathrm{CO}$ ) and minima in those of stratospheric origin (like ozone) (Park et al., 2007). Much of the transport from the surface to the upper troposphere is likely caused by convective updrafts which are not resolved in current reanalysis products, and large uncertainties arise for the transport of air from the surface to the upper troposphere (Bergman et al., 2013). Here, we focus on transport pathways of air that have already reached the upper-tropospheric anticyclone. Isentropic trajectory calculations showed that air parcels initialized within the anticyclone at $360 \mathrm{~K}$ are relatively well confined in the anticyclone for about 10-20 days. However, after 15-20 days, a considerable fraction of air parcels is shed to the east and west of the anticyclone, and also to the south across the Equator. After 30 days, trajectories are widely spread across the tropical belt. The shedding of air is in agreement with variability observed in PV fields and tracer distributions (Randel and Park, 2006; Popovic and Plumb, 2001, GR2013). Despite strong PV streamer activity associated with the exchange of air masses between tropics and extratropics in the vicinity of the anticyclone region reported by Kunz et al. (2015), we find that only a small fraction $(3 \%)$ of the trajectories reaches the northern extratropics (poleward of $45^{\circ} \mathrm{N}$ ) within 30 days. Due to the different setup of the two studies, our results are not directly comparable to those of Kunz et al. (2015). However, most (80-95\%) of the air mass exchange across the tropical barrier found by Kunz et al. (2015) occurs equatorward, and trajectories that take part in transport across the barrier are not located in the anticyclone core at 360 and $380 \mathrm{~K}$ (see Fig. 9a and b in Kunz et al., 2015); thus, the small fraction of trajectories transported poleward in our 
study does not necessarily contradict Kunz et al. (2015). At higher levels $(380 \mathrm{~K})$, the anticyclone is more confined compared to $360 \mathrm{~K}$, and trajectories are less likely to be spread across the tropical belt. This is consistent with the finding by Ploeger et al. (2015) that a transport barrier for the anticyclone can be defined at $380 \mathrm{~K}$ but not at $360 \mathrm{~K}$. However, more trajectories reach the extratropics after 30 days at the $380 \mathrm{~K}$ level (8\%) compared to $360 \mathrm{~K}(3 \%)$.

Using three-dimensional trajectory calculations, we found that a considerable fraction of air parcels initially located within the upper-tropospheric anticyclone (at $360 \mathrm{~K}$ ) reach the stratosphere within 60 days ( $31 \%$ for kinematic and $48 \%$ for diabatic trajectory calculations). The horizontal confinement over 10-20 days is sufficiently long to efficiently transport air upward and into the stratosphere: typical transit times from the anticyclone at $360 \mathrm{~K}$ to the tropopause are 10 15 days.

The most likely pathway from the upper-tropospheric anticyclone into the stratosphere is ascent within the anticyclone region. In the mean, air masses move upward and across the (sub-)tropical tropopause, as shown in Fig. 6. A very similar pattern of transport of an idealized tracer through the monsoon anticyclone was reported by Orbe et al. (2015) (their Fig. 4), based on tracer experiments in a global chemistryclimate model. A small fraction of air is transported from the upper-tropospheric anticyclone to the northern extratropical lower stratosphere, likely by isentropic mixing. Vogel et al. (2014) report on recent observations of this pathway, but in our study this pathway is found to be of minor importance. Rather, vertical advection is more efficient at transporting air from the upper-tropospheric anticyclone into the stratosphere as compared to isentropic mixing into the extratropical stratosphere. Thus, pollutants that are transported by convection into the upper troposphere can be transported into the tropical pipe and further into the deep stratosphere.

The results presented here on the role of different transport pathways of air from the upper-tropospheric anticyclone to the stratosphere were found to be robust against the details of trajectory initialization. While results differ when using kinematic versus diabatic vertical velocities, the overall conclusions are valid for both methods. It is known that heating rates are likely overestimated in the upper troposphere in ERA-Interim (Wright and Fueglistaler, 2013; Randel and Jensen, 2013). However, even when reducing heating rates to half their value, a considerable fraction of trajectories reaches the stratosphere after 60 days, and the relative role of transport pathways remains the same.

Outflow from tropical deep convection is estimated by previous studies to be found around levels of 340 to $370 \mathrm{~K}$ (Folkins and Martin, 2005; Wright et al., 2011; Tzella and Legras, 2011; Bergman et al., 2012), consistent with the patterns of large-scale divergence in reanalyses (Fig. 1). Calculation of transport initialized over levels 340-380 K shows that air is far more likely to be advected to the stratosphere by large-scale (resolved) winds when injected at $360 \mathrm{~K}$ or above (Fig. 15). Air parcels injected below $360 \mathrm{~K}$ only reach the stratosphere with a probability of less than $20 \%$, despite strong positive heating rates between 340 to $350 \mathrm{~K}$ in the monsoon region. Our results suggest that the lack of confinement of air parcels to the region of upward transport below $360 \mathrm{~K}$ results in the low probability of rising air parcels. Only at $360 \mathrm{~K}$ and above, where the anticyclone confines air to the region of lifting, can large-scale winds effectively transport air upward. Thus, our calculations suggest that deep convection needs to transport air to levels around $360 \mathrm{~K}$ in order to be advected further upward by the large-scale circulation. This results is in line with recent findings by Tissier and Legras (2015), who show that air at $380 \mathrm{~K}$ with convective sources in the Asian monsoon region, originates from cloud tops of about 355 to $365 \mathrm{~K}$ (see their Fig. 3). Tissier and Legras (2015) report transit times from cloud tops to $380 \mathrm{~K}$ of about 20-30 days for the Asian monsoon region, approximately in line with transit times of 15-20 days from 360 to $380 \mathrm{~K}$ found here.

The calculations and results shown here are relevant to the observations of transport of volcanic gases and aerosols in the monsoon region associated with the eruption of Mt. Nabro in June 2011 (Bourassa et al., 2012). Briefly, the Nabro eruption injected gases and aerosols into the upper troposphere and lower stratosphere, resulting in the formation of an enhanced aerosol layer in the lower-stratosphere monsoon region approximately 2 to 4 weeks later. The time lag is consistent with conversion of volcanic sulfur dioxide to sulfate aerosol (Weisenstein et al., 1997), with details that can depend on altitude (see Penning de Vries at al. (2014) and references therein). While there is some debate regarding the altitude of the plume injection heights (Vernier et al., 2013; Fromm et al., 2013, 2014), Clarisse et al. (2014) suggest that the main injection occurred over altitudes of 15$17 \mathrm{~km}$ consistent, with observed plume trajectories, as shown in Bourassa et al. (2013). The stratospheric aerosol layer occurred at somewhat higher altitudes (above $18 \mathrm{~km}$; Bourassa et al., 2012; Fairlie et al., 2014), consistent with slow upward transport in the monsoon circulation. Fairlie et al. (2014) furthermore show that the stratospheric aerosol plume continued to move upward during the summer at a rate of about $10 \mathrm{~K} \mathrm{month}^{-1}$, reasonably consistent with the trajectory calculations in this work. Overall our calculations of large-scale upward transport within the monsoon circulation, including transport into the lower stratosphere, are consistent with the evolution of the unique Nabro event.

Acknowledgements. We thank S. Brinkop, M. Nützel and J. Bergman for comments on the manuscript and P. Jöckel for assistance with the ECMWF data. Three anonymous reviewers provided constructive comments which significantly improved the manuscript. We thank the ECMWF for providing the ERA-Interim data. This study was partially funded by the Deutsche Forschungsgemeinschaft (DFG) through the DFG research group SHARP (Stratospheric Change and its Role for Climate Prediction) and 
by the Helmholtz Association under grant number VH-NG-1014 (Helmholtz-Hochschul-Nachwuchsforschergruppe MACClim). This work was partially supported by the NASA Aura Science Program. The National Center for Atmospheric Research is operated by the University Corporation for Atmospheric Research, under sponsorship of the National Science Foundation.

The article processing charges for this open-access publication were covered by a Research

Centre of the Helmholtz Association.

Edited by: G. Stiller

\section{References}

Abalos, M., Ploeger, F., Konopka, P., Randel, W. J., and Serrano, E.: Ozone seasonality above the tropical tropopause: reconciling the Eulerian and Lagrangian perspectives of transport processes, Atmos. Chem. Phys., 13, 10787-10794, doi:10.5194/acp13-10787-2013, 2013.

Baker, A. K., Schuck, T. J., Slemr, F., van Velthoven, P., Zahn, A., and Brenninkmeijer, C. A. M.: Characterization of nonmethane hydrocarbons in Asian summer monsoon outflow observed by the CARIBIC aircraft, Atmos. Chem. Phys., 11, 503518, doi:10.5194/acp-11-503-2011, 2011.

Bergman, J. W., Jensen, E. J., Pfister, L., and Yang, Q.: Seasonal differences of vertical-transport efficiency in the tropical tropopause layer: on the interplay between tropical deep convection, largescale vertical ascent, and horizontal circulations, J. Geophys. Res., 117, D05302, doi:10.1029/2011JD016992, 2012.

Bergman, J. W., Fierli, F., Jensen, E. J., Honomichl, S., and Pan, L. L.: Boundary layer sources for the Asian anticyclone: regional contributions to a vertical conduit, J. Geophys. Res., 118, 2560-2575, doi:10.1002/jgrd.50142, 2013.

Bourassa, A., Robock, A., Randel, W., Deshler, T., Rieger, L., Lloyd, N., Llewellyn, E., and Degenstein, D. A.: Large volcanic aerosol load in the stratosphere linked to Asian monsoon transport, Science, 337, 78-81, doi:10.1126/science.1219371, 2012.

Bourassa, A. E., Robock, A., Randel, W. J., Deshler, T., Rieger, L. A., Lloyd, N. D., Llewellyn, E. J., and Degenstein, D. A.: Response to comments on "Large volcanic aerosol load in the stratosphere linked to the Asian monsoon transport", Science, 339, 6120, doi:10.1126/science.1227961, 2013.

Clarisse, L., Coheur, P.-F., Theys, N., Hurtmans, D., and Clerbaux, C.: The 2011 Nabro eruption, a $\mathrm{SO}_{2}$ plume height analysis using IASI measurements, Atmos. Chem. Phys., 14, 3095-3111, doi:10.5194/acp-14-3095-2014, 2014.

Dee, D. P., Uppala, S. M., Simmons, A. J., Berrisford, P., Poli, P., Kobayashi, S., Andrae, U., Balmaseda, M. A., Balsamo, G., Bauer, P., Bechtold, P., Beljaars, A. C. M., van de Berg, L., Bidlot, J., Bormann, N., Delsol, C., Dragani, R., Fuentes, M., Geer, A. J., Haimberger, L., Healy, S. B., Hersbach, H., Holm, E. V., Isaksen, L., Kållberg, P., Köhler, M., Matricardi, M., McNally, A. P., Monge-Sanz, B. M., Morcrette, J.-J., Park, B.K., Peubey, C., de Rosnay, P., Tavolato, C., Thepaut, J.-N., and Vitart, F.: The ERA-Interim reanalysis: configuration and performance of the data assimilation system, Q. J. Roy. Meterol. Soc., 137, 553-597, doi:10.1002/qj.828, 2011.
Dethof, A., O’Neill, A., Slingo, J. M., and Smit, H. G. J.: A mechanism for moistening the lower stratosphere involving the Asian summer monsoon, Q. J. Roy. Meteorol. Soc., 125, 1079-1106, 1999.

Diallo, M., Legras, B., and Chédin, A.: Age of stratospheric air in the ERA-Interim, Atmos. Chem. Phys., 12, 12133-12154, doi:10.5194/acp-12-12133-2012, 2012.

Fairlie, T. D., Vernier, J.-P., Natarajan, M., and Bedka, K. M.: Dispersion of the Nabro volcanic plume and its relation to the Asian summer monsoon, Atmos. Chem. Phys., 14, 7045-7057, doi:10.5194/acp-14-7045-2014, 2014.

Folkins, I. and Martin, R.: The vertical structure of tropical convection and its impact on the budgets of water vapor and ozone, J. Atmos. Sci., 62, 1560-1573, 2005.

Fromm, M., Nedoluha, G., and Charvat, Z.: Comment on "Large volcanic aerosol load in the stratosphere linked to Asian monsoon transport", Science, 339, 647, doi:10.1126/science.1228605, 2013.

Fromm, M., Kablick III, G., Nedoluha, G., Carboni, E., Grainger, R., Campbell, J., and Lewis, J.: Correcting the record of volcanic stratospheric aerosol impact: Nabro and Sarychev Peak, J. Geophys. Res.-Atmos., 119, 10343-10364, doi:10.1002/2014JD021507, 2014.

Fueglistaler, S., Dessler, A. E., Dunkerton, T. J., Folkins, I., Fu, Q., and Mote, P. W.: Tropical tropopause layer, Rev. Geophys., 47, RG1004, doi:10.1029/2008RG000267, 2009.

Garny, H. and Randel, W.: Dynamical variability in the Asian monsoon anticyclone observed in potential vorticity and correlations with tracer distributions, J. Geophys. Res.-Atmos., 118, 1-13, 2013.

Gettelman, A., Forster, P., Fujiwara, M., Fu, Q., Vomel, H., Gohar, L. K., Johanson, C., and Ammerman, M.: Radiation balance of the tropical tropopause layer, J. Geophys. Res., 109, D07103, doi:10.1029/2003JD004190, 2004.

Konopka, P., Grooß, J.-U., Ploeger, F., and Müller, R.: Annual cycle of horizontal in-mixing into the lower tropical stratosphere, J. Geophys. Res., 114, D19111, doi:10.1029/2009JD011955, 2009.

Kunz, A., Sprenger, M., and Wernli, H.: Climatology of potential vorticity streamers and associated isentropic transport pathways across PV gradient barriers, J. Geophys. Res., 120, 3802-3821, doi:10.1002/2014JD022615, 2015.

Li, Q., Jacob, D. J., Logan, J. A., Bey, I., Yantosca, R. M., Liu, H., Martin, R. V., Fiore, A. M., Field, B. D., Duncan, B. N., and Thouret, V.: A tropospheric ozone maximum over the Middle East, Geophys. Res. Lett., 28, 3235-3238, 2001.

Liebmann, B. and Smith, C.: Description of a complete (interpolated) outgoing longwave radiation dataset, B. Am. Meteorol Soc., 77, 1275-1277, 1996.

Liu, J. J., Jones, D. B. A., Worden, J. R., Noone, D., Parrington, M., and Kar, J.: Analysis of the summertime buildup of tropospheric ozone abundances over the Middle East and North Africa as observed by the Tropospheric Emission Spectrometer instrument, J. Geophys. Res., 114, D05304, doi:10.1029/2008JD010993, 2009.

Liu, J. J., Jones, D. B. A., Zhang, S., and Kar, J.: Influence of interannual variations in transport on summertime abundances of ozone over the Middle East, J. Geophys. Res., 116, D20310, doi:10.1029/2011JD016188, 2011.

Mote, P. W., Rosenlof, K. H., McIntyre, M. E., Carr, E. S., Gille, J. C., Holton, J. R., Kinnersley, J. S., Pumphrey, H. C., 
Russell, J. M., and Waters, J. W.: An atmospheric tape recorder: the imprint of tropical tropopause temperatures on stratospheric water vapor, J. Geophys. Res., 101, 3989-4006, 1996.

Orbe, C., Waugh, D., and Newman, P.: Air-mass origins in the tropical lower stratosphere: the influence of the Asian boundary layer, Geophys. Res. Lett., 42, 4240-4248, doi:10.1002/2015GL063937, 2015.

Park, M., Randel, W. J., Gettelman, A., Massie, S. T., and Jiang, J. H.: Transport above the Asian summer monsoon anticyclone inferred from Aura Microwave Limb Sounder tracers, J. Geophys. Res., 112, D16309, doi:10.1029/2006JD008294, 2007.

Park, M., Randel, W. J., Emmons, L. K., Bernath, P. F., Walker, K. A., and Boone, C. D.: Chemical isolation in the Asian monsoon anticyclone observed in Atmospheric Chemistry Experiment (ACE-FTS) data, Atmos. Chem. Phys., 8, 757-764, doi:10.5194/acp-8-757-2008, 2008.

Park, M., Randel, W. J., Kinnison, D. E., Emmons, L. K., Bernath, P. F., Walker, K. A., Boone, C. D., and Livesey, N. J.: Hydrocarbons in the upper troposphere and lower stratosphere observed from ACE-FTS and comparisons with WACCM, J. Geophys. Res.-Atmos., 118, 1964-1980, doi:10.1029/2012JD018327, 2013.

Penning de Vries, M. J. M., Dörner, S., Pukite, J., Hörmann, C., Fromm, M. D., and Wagner, T.: Characterisation of a stratospheric sulfate plume from the Nabro volcano using a combination of passive satellite measurements in nadir and limb geometry, Atmos. Chem. Phys., 14, 8149-8163, doi:10.5194/acp-148149-2014, 2014.

Ploeger, F., Konopka, P., Gunther, G., Grooß, J.-U., and Müller, R.: Impact of the vertical velocity scheme on modeling transport in the tropical tropopause layer, J. Geophys. Res., 115, D03301, doi:10.1029/2009JD012023, 2010.

Ploeger, F., Fueglistaler, S., Grooß, J.-U., Günther, G., Konopka, P., Liu, Y. S., Müller, R., Ravegnani, F., Schiller, C., Ulanovski, A., and Riese, M.: Insight from ozone and water vapour on transport in the tropical tropopause layer (TTL), Atmos. Chem. Phys., 11, 407-419, doi:10.5194/acp-11-407-2011, 2011.

Ploeger, F., Konopka, P., Müller, R., Fueglistaler, S., Schmidt, T., Manners, J. C., Grooß, J.-U., Günther, G., Forster, P. M., and Riese, M.: Horizontal transport affecting trace gas seasonality in the Tropical Tropopause Layer (TTL), J. Geophys. Res., 117, D0930, doi:10.1029/2011JD017267, 2012.

Ploeger, F., Gottschling, C., Griessbach, S., Grooß, J.-U., Günther, G., Konopka, P., Müller, R., Riese, M., Stroh, F., Tao, M., Ungermann, J., Vogel, B., and von Hobe, M.: A potential vorticitybased determination of the transport barrier in the Asian summer monsoon anticyclone, Atmos. Chem. Phys., 15, 13145-13159, doi:10.5194/acp-15-13145-2015, 2015.

Popovic, J. M. and Plumb, R. A.: Eddy shedding from the upper tropospheric Asian monsoon anticyclone, J. Atmos. Sci., 58, 93$104,2001$.
Pumphrey, H., Boone, C., Walker, K., Bernath, P., and Livesey, N.: Tropical tape recorder observed in HCN, Geophys. Res. Lett., 35, L05801, doi:10.1029/2007GL032137, 2008.

Randel, W. J. and Jensen, E.: Physical processes in the tropical tropopause layer and their role in a changing climate, Nat. Geosci., 6, 169-176, 2013.

Randel, W. J. and Park, M.: Deep convective influence on the Asian summer monsoon anticyclone and associated tracer variability observed with Atmospheric Infrared Sounder (AIRS), J. Geophys. Res., 111, D12314, doi:10.1029/2005JD006490, 2006.

Randel, W. J., Park, M., Emmons, L., Kinnison, D., Bernath, P., Walker, K. A., Boone, C., and Pumphrey, H.: Asian monsoon transport of pollution to the stratosphere, Science, 328, 611-613, doi:10.1126/science.1182274, 2010.

Schoeberl, M. R. and Dessler, A. E.: Dehydration of the stratosphere, Atmos. Chem. Phys., 11, 8433-8446, doi:10.5194/acp11-8433-2011, 2011.

Schoeberl, M. R., Dessler, A. E. and Wang, T.: Dehydration of the stratosphere, Atmos. Chem. Phys., 12, 6475-6487, doi:10.5194/acp-12-6475-2012, 2012.

Tissier, A.-S. and Legras, B.: Transport across the tropical tropopause layer and convection, Atmos. Chem. Phys. Discuss., 15, 26231-26271, doi:10.5194/acpd-15-26231-2015, 2015.

Tzella, A. and Legras, B.: A Lagrangian view of convective sources for transport of air across the Tropical Tropopause Layer: distribution, times and the radiative influence of clouds, Atmos. Chem. Phys., 11, 12517-12534, doi:10.5194/acp-11-12517-2011, 2011.

Vernier, J.-P., Thomason, L., Fairlie, T. D., Minnis, P., Palikonda, R., and Bedka, K. M.: Comment on "Large volcanic aerosol load in the stratosphere linked to Asian monsoon transport", Science, 339, 6120, doi:10.1126/science.1227817, 2013.

Vogel, B., Günther, G., Müller, R., Grooß, J.-U., Hoor, P., Krämer, M., Müller, S., Zahn, A., and Riese, M.: Fast transport from Southeast Asia boundary layer sources to northern Europe: rapid uplift in typhoons and eastward eddy shedding of the Asian monsoon anticyclone, Atmos. Chem. Phys., 14, 12745-12762, doi:10.5194/acp-14-12745-2014, 2014.

Weisenstein, D. K., Yue, G. K., Ko, M. K. W., Sze, N.-D., Rodriguez, J. M., and Scott, C. J.: A two-dimensionalmodel of sulfur species and aerosols, J. Geophys. Res., 102, 13019-13035, 1997.

Wright, J. S. and Fueglistaler, S.: Large differences in reanalyses of diabatic heating in the tropical upper troposphere and lower stratosphere, Atmos. Chem. Phys., 13, 9565-9576, doi:10.5194/acp-13-9565-2013, 2013.

Wright, J. S., Fu, R., Fueglistaler, S., Liu, Y. S., and Zhang, Y.: The influence of summertime convection over Southeast Asia on water vapor in the tropical stratosphere, J. Geophys. Res., 116, D12302, doi:10.1029/2010JD015416, 2011. 